\title{
Degradation of Reactive Black 5 in a submerged photocatalytic membrane distillation reactor with microwave electrodeless lamps
} as light source

\author{
Dan $\mathrm{Qu}^{\mathrm{a}, *}$, Zhimin Qiang ${ }^{\mathrm{b}}$, Shuhu Xiao ${ }^{\mathrm{c}}$, Qingxiang Liu ${ }^{\mathrm{a}}$, Yuqing Lei ${ }^{\mathrm{a}}$, Tuantuan Zhou ${ }^{\mathrm{a}}$ \\ ${ }^{a}$ College of Environmental Science and Engineering, Beijing Forestry University, Beijing 100083, China \\ ${ }^{\mathrm{b}}$ Research Center for Eco-Environmental Sciences, Chinese Academy of Sciences, Beijing 100085, China \\ ${ }^{\mathrm{c}}$ State Key Laboratory of Environmental Criteria and Risk Assessment, Chinese Research Academy of Environmental Sciences, Beijing 100012, China
}

\section{A R T I C L E I N F O}

\section{Article history:}

Received 17 September 2013

Received in revised form 31 October 2013

Accepted 1 November 2013

Available online 9 November 2013

\section{Keywords:}

Submerged photocatalytic membrane

distillation reactor

Microwave electrodeless lamp

Vacuum membrane distillation

Reactive Black 5

Photodegradation

\begin{abstract}
A B S T R A C T
A novel submerged photocatalytic membrane distillation reactor (SPMDR) was developed and microwave electrodeless lamps were applied as the source light. Reactive Black 5 was used as a model dye with an initial concentration of $400 \mathrm{mg} / \mathrm{L}$. The effects of $\mathrm{TiO}_{2}$ dose and feed temperature on the photodegradation efficiency and permeate flux were first investigated. The highest degradation rate was observed at $2.0 \mathrm{~g} / \mathrm{L}$ $\mathrm{TiO}_{2}$ and $65{ }^{\circ} \mathrm{C}$. The permeate flux decreased by $15.8 \%$ when the $\mathrm{TiO}_{2}$ dose increased from 0.5 to $6.0 \mathrm{~g} / \mathrm{L}$. The permeate flux of the SPMDR in the presence of $2.0 \mathrm{~g} / \mathrm{L} \mathrm{TiO}_{2}$ was higher than the pure water flux using conventional heating, which confirms the enhancement of microwave irradiation to the membrane distillation mass transfer. The SPMDR achieved a high color $(100 \%)$ and TOC $(80.1 \%)$ removal efficiency after $300 \mathrm{~min}$ reaction. The byproducts identified in the feed included aliphatic acids (formic, acetic and maleic) and inorganic ions $\left(\mathrm{SO}_{4}^{2-}, \mathrm{NH}_{4}^{+}\right.$and $\left.\mathrm{NO}_{3}^{-}\right)$. The SPMDR produced high quality water because dye, $\mathrm{TiO}_{2}$ and inorganic ions were completely retained in the feed side. Formic and acetic acids were detected in the permeate side with amounts of 0.08 and $0.25 \mathrm{mg}$ (i.e., 1.83 and $5.29 \mathrm{mg} / \mathrm{L}$ ), respectively. Scanning electron microscope (SEM) images showed that a loose $\mathrm{TiO}_{2}$ cake layer was formed on the membrane surface, which decreased the membrane porosity and contact angle to some extent. However, the module efficiency, porosity and contact angle could be largely recovered after 30 min of washing with distilled water.
\end{abstract}

(c) 2013 Elsevier B.V. All rights reserved.

\section{Introduction}

Titanium dioxide $\left(\mathrm{TiO}_{2}\right)$ is generally used as one of the most popular photocatalysts because of its good photocatalytic activity, high stability, nontoxicity, chemical inertness, and low cost [1]. However, the separation and reuse of $\mathrm{TiO}_{2}$ powder remain a big challenge for its practical application. Photocatalytic membrane reactors (PMRs) combine the photocatalysis and membrane processes together, in which the membrane acts as a barrier for $\mathrm{TiO}_{2}$ and byproducts and thus enables the continuous separation of $\mathrm{TiO}_{2}$ [2]. Most PMRs described in the literature adopt a pressuredriven membrane process such as microfiltration (MF) [2-5], ultrafiltration (UF) $[2,6,7]$ and nanofiltration (NF) $[2,8-11]$, which leads to a severe permeate flux decline because of $\mathrm{TiO}_{2}$ particles. Furthermore, the permeate has an unsatisfactory quality because small molecules can pass easily through the membrane, even in the case of NF.

\footnotetext{
* Corresponding author. Tel.: +861013811836963.

E-mail address: qudana@163.com (D. Qu).
}

Recently, a new type of PMR that combines photocatalysis with hydrophobic membrane distillation (MD) has been reported $[8$, $12-17]$. Since the MD is a thermally driven process, only volatile components in the feed can pass through the pores of the hydrophobic membrane to the permeate side. This enables the production of pure water if the feed only contains non-volatiles. Compared with the pressure-driven membrane process, the MD is less prone to fouling because it is operated at an ambient pressure [18].

Mozia et al. developed a photocatalytic membrane distillation reactor (PMDR) for azo dye degradation, which combined hybrid photocatalysis with direct contact membrane distillation (DCMD) [8,12-17]. Low-pressure mercury vapor UV lamps were positioned above the feed tank in which photocatalytic degradation took place. The mixture of a synthetic dye wastewater and $\mathrm{TiO}_{2}$ particles in the feed tank was pumped through a heat exchanger to the membrane module for separation. The feed flowed inside the hollow fibers whereas the permeate flowed outside. The results showed that the MD process was effective in separating $\mathrm{TiO}_{2}$ particles with an insignificant flux decline and a high quality permeate. 
In this study, a novel submerged photocatalytic membrane distillation reactor (SPMDR) was developed using microwave electrodeless discharge lamps (MEDLs) as the light source. The MD process selected was vacuum membrane distillation (VMD). The MEDLs, powered by microwave, have been widely used in photocatalytic processes because of its low cost, simple equipment, and high photochemical efficiency [1,19-21]. In addition to the benefits of a conventional PMDR, such as high quality permeate and alleviated membrane fouling, a significant advantage of the developed SPMDR is that microwave irradiation can enhance both the photocatalysis efficiency and the VMD mass transfer. Temperature polarization widely exists in the MD process, which will decrease the mass transfer efficiency. Microwave irradiation can provide homogeneous heating to increase a local temperature, which compensates for the temperature decrease caused by evaporation and temperature polarization. Ji et al. reported that microwave irradiation could increase the mass transfer coefficient by $27.7 \%$ during a VMD process and enabled high permeate fluxes even at a low feed flow rate [22].

Reactive Black 5 (RB5) with a high concentration was used as a model azo dye to be degraded by the developed SPMDR. The effects of $\mathrm{TiO}_{2}$ dose and feed temperature on the photodegradation efficiency and permeate flux was investigated. The decolorization and mineralization of RB5 as well as the rejection of VMD toward $\mathrm{TiO}_{2}$, dye and photodegradation byproducts were assessed. Moreover, membrane fouling was examined.

\section{Experimental}

\subsection{Materials and reagents}

RB5 $\left(\mathrm{C}_{26} \mathrm{H}_{21} \mathrm{~N}_{5} \mathrm{Na}_{4} \mathrm{O}_{19} \mathrm{~S}_{6}\right)$ was purchased from Beijing Dongxiyi Ltd., Co. (China). A commercially available $\mathrm{TiO}_{2}$ (Aeroxide P25, Evonik, Germany) was used as the photocatalyst. U-shaped quartz MEDLs (Jimin Illumination Equipment Factory, Shanghai, China), filled with $20 \mathrm{mg} \mathrm{Hg}$ and 5.0 Torr Ar, were used as the light source. The MEDLs emitted UV and visible lights upon microwave irradiation. The irradiation spectrum showed peaks at 254, 312, 365, 405 and $435 \mathrm{~nm}$, and the main UV wavelength was $254 \mathrm{~nm}$ (provided by the manufacturer). The hydrophobic polyvinylidene fluoride (PP) hollow-fiber membrane was obtained from Hangzhou Kaijie Membrane Company (China), with an average pore size of $0.2 \mu \mathrm{m}$, a porosity of $40-45 \%$, and an inside and outside diameter of 400 and $500 \mu \mathrm{m}$, respectively. The membrane module consisted of 60 hollow fibers, with an effective area of $0.039 \mathrm{~m}^{2}$ (calculated from the outside diameter).

\subsection{The submerged photocatalytic membrane distillation reactor (SPMDR)}

The SPMDR is schematically illustrated in Fig. 1. A cylindrical glass reactor (outer diameter $150 \mathrm{~mm}$ and height $250 \mathrm{~mm}$ ) was housed in a modified microwave oven $(1300 \mathrm{~W}, 2.45 \mathrm{GHz})$. The membrane module was submerged in the working solution. The MEDLs floated on the solution with approximately $60 \%$ of immersion. The feed temperature was controlled by circulating the solution through a cooler (DC 510, Xinzhi Biotechnology, China) via a magnetic pump (MP20RM, Seisun Pump, China). A vacuum pump (DOA-P504-BN, GAST, USA) was used as the driving force and the transmembrane vapor was condensed and collected in a permeate reservoir.

\subsection{The degradation of RB5 in the SPMDR}

The effects of $\mathrm{TiO}_{2}$ dose and feed temperature on the photodegradation efficiency and permeate flux were first investigated under the following experimental conditions: $400 \mathrm{mg} / \mathrm{L}$ of initial RB5 concentration $\left(C_{\mathrm{o}, \mathrm{RB} 5}\right), 1500 \mathrm{~mL}$ of reaction solution, $-75 \mathrm{kPa}$ of vacuum pressure $\left(P_{\mathrm{vac}}\right)$, and $300 \mathrm{~min}$ of reaction time. The feed samples $(10 \mathrm{~mL}$ each) were taken every $30 \mathrm{~min}$ and filtered through $0.45 \mu \mathrm{m}$ membrane filters before analysis. The UV-vis spectra of the samples were scanned over a wavelength range of 200-900 nm using a Hitachi UV-2600 spectrophotometer (Japan). The RB5 concentration in the feed was determined by measuring its absorbance at $600 \mathrm{~nm}$. Total organic carbon (TOC) was analyzed with a Shimadzu TOC-VCSN analyzer (Japan). Aliphatic acids and inorganic ions were detected with ion chromatograph (IC 3000, Dionex, USA). The permeate conductivity was measured by a DDS-307 conductivity meter (China). The permeate flux was calculated by the following equation:

$J=\frac{V}{A n t}$

where $J$ is the permeate flux, $\mathrm{L} / \mathrm{m}^{2} \mathrm{~h} ; V$ is the permeate volume, $\mathrm{L} ; A$ is the area of one hollow fiber, $\mathrm{m}^{2} ; n$ is the number of hollow fibers; and $t$ is the elapsed time, $\mathrm{h}$.

\subsection{Characterization of the hollow-fiber membrane}

The outer surface morphology of the PP membrane was viewed with a scanning electron microscope (SEM, S-3000N, Hitachi, Japan). Membrane samples were frozen in liquid nitrogen, fractured to obtain fragments, and then sputtered with platinum by using a HITACHIE-1010 ion sputtering device. Membrane porosity was determined gravimetrically by weighing the liquid contained in membrane pores [23]. The contact angle $(\theta)$ of the hollow fiber was measured by a tensiometer (DCAT 11, Dataphysics, China).

\section{Results and discussion}

\subsection{Effect of $\mathrm{TiO}_{2}$ dose on photodegradation efficiency and permeate} flux

In the SPMDR, the feed volume decreased continuously because of water vapor transferring to the permeate side. Since the

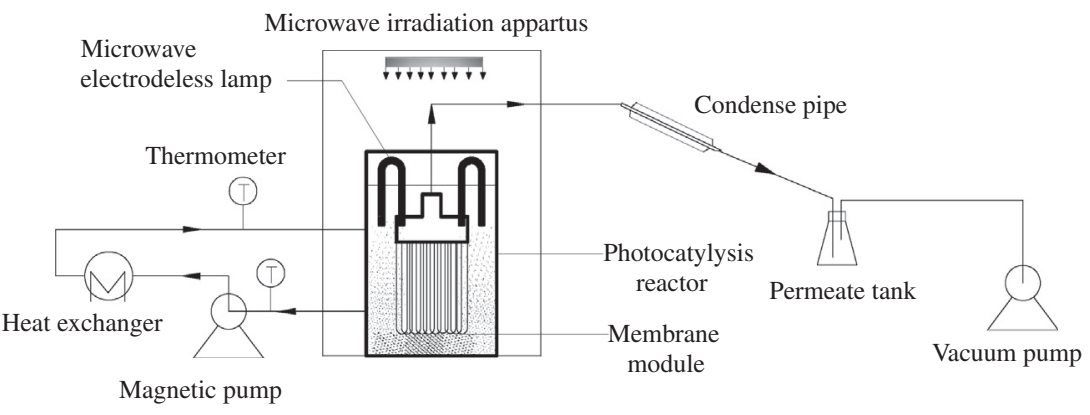

Fig. 1. Schematic diagram of the submerged photocatalytic membrane distillation reactor. 
permeate flux varied under different conditions, the change in the RB5 amount, instead of its concentration, was plotted as a function of time at different $\mathrm{TiO}_{2}$ doses. Fig. 2 shows that the $\mathrm{RB} 5$ removal efficiency reached approximately $75 \%$ in the absence of $\mathrm{TiO}_{2}$ within 300 min, most probably due to the destruction of azo bonds by UV light emitted by the MEDLs [1]. The addition of $\mathrm{TiO}_{2}(0.5-6.0 \mathrm{~g} / \mathrm{L})$ could enhance dye degradation, and a complete removal was achieved for all runs within $300 \mathrm{~min}$. The maximum reaction rate of RB5 was observed at a $\mathrm{TiO}_{2}$ dose of $2.0 \mathrm{~g} / \mathrm{L}$, while further increasing the $\mathrm{TiO}_{2}$ dose (i.e., 4.0 and $6.0 \mathrm{~g} / \mathrm{L}$ ) led to a decrease in the reaction rate. That was because a high $\mathrm{TiO}_{2}$ dose would decrease the solution transmittance to UV light and thus reduce the photocatalytic reaction rate [24]; and moreover, the $\mathrm{TiO}_{2}$ particles would agglomerate and thus lose partially the available photocatalytic surface area [25].

The permeate flux as a function of time at different $\mathrm{TiO}_{2}$ doses is shown in Fig. 3. The permeate flux decreased slightly with an increasing $\mathrm{TiO}_{2}$ doses. The average permeate flux at $0.5 \mathrm{~g} / \mathrm{L} \mathrm{TiO}$ was $4.56 \mathrm{~L} / \mathrm{m}^{2} \mathrm{~h}$, which was close to that measured with pure water $\left(4.64 \mathrm{~L} / \mathrm{m}^{2} \mathrm{~h}\right)$. However, it decreased to $3.74 \mathrm{~L} / \mathrm{m}^{2} \mathrm{~h}$ at $6.0 \mathrm{~g} / \mathrm{L} \mathrm{TiO}_{2}$. It is noted that the permeate flux increased gradually during the initial $60 \mathrm{~min}$ of each run and thereafter remained approximately stable. During the initial reaction period, the feed temperature was increased gradually from an ambient value to $65^{\circ} \mathrm{C}$, thus leading to an increase in the permeate flux. After the feed temperature reached stable (i.e. $65^{\circ} \mathrm{C}$ ), a steady-state permeate flux was achieved.

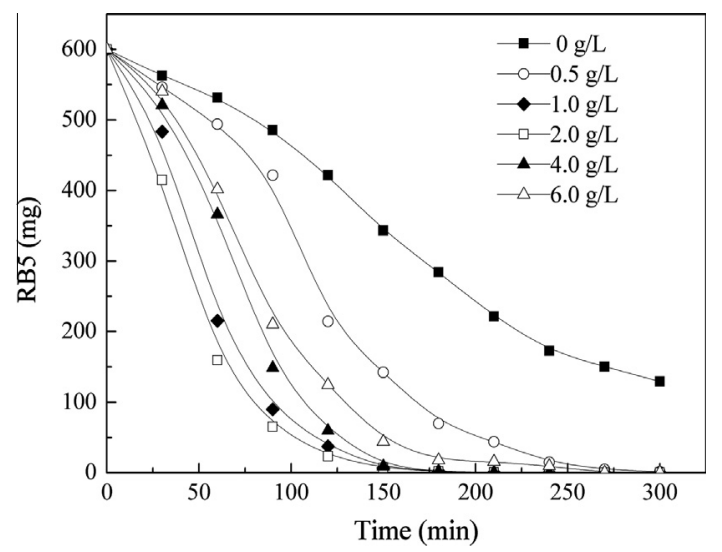

Fig. 2. Change in the RB5 amount in the feed during the photodegradation process at different $\mathrm{TiO}_{2}$ doses $\left(\boldsymbol{C}_{\mathbf{o}, \mathrm{RB} 5}=400 \mathrm{mg} / \mathrm{L}, T=65^{\circ} \mathrm{C}, P_{\text {vac }}=-75 \mathrm{kPa}\right)$.

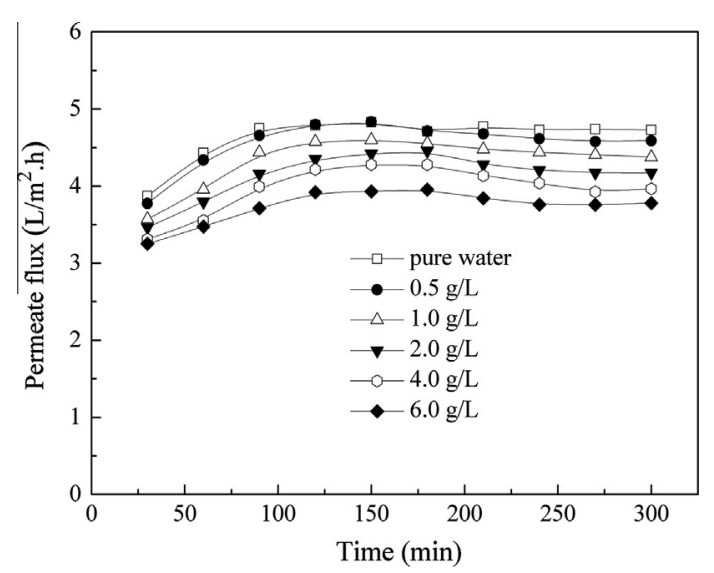

Fig. 3. Change of the permeate flux during the photodegradation process at different $\mathrm{TiO}_{2}$ doses $\left(\boldsymbol{C}_{\mathbf{o}, \mathrm{RB} 5}=400 \mathrm{mg} / \mathrm{L}, T=65^{\circ} \mathrm{C}, P_{\mathrm{vac}}=-75 \mathrm{kPa}\right)$.
Mozia et al. reported that the $\mathrm{TiO}_{2}$ dose $(0.1-0.5 \mathrm{~g} / \mathrm{L})$ had no impact on the permeate flux in the DCMD process $[8,12,13]$. However, membrane fouling was observed in the current study. The permeate flux decreased by $15.8 \%$ when the $\mathrm{TiO}_{2}$ dose increased from 0.5 to $6.0 \mathrm{~g} / \mathrm{L}$. To investigate the membrane fouling, the PP membrane module had been operated continuously for $25 \mathrm{~h}$ at various $\mathrm{TiO}_{2}$ doses, and then it was washed with distilled water for $30 \mathrm{~min}$. The permeate flux was restored to $4.05 \mathrm{~L} / \mathrm{m}^{2} \mathrm{~h}$ after washing. In comparison, severe membrane fouling was observed in the pressure-driven membrane processes. For example, during an MF process with $\mathrm{TiO}_{2}$ suspension, the permeate flux declined significantly by $15 \%, 64 \%$ and $94 \%$ at $\mathrm{TiO}_{2}$ doses of $0.01,0.1$ and $1.0 \mathrm{~g} / \mathrm{L}$, respectively [4]. Additionally, in a hybrid photocatalysis-NF system, the permeate flux decreased quickly from 54 to $33 \mathrm{~L} / \mathrm{m}^{2} \mathrm{~h}$ in the presence of suspended $\mathrm{TiO}_{2}$ [10]. Therefore, the developed SPMSR is more resistant to membrane fouling than the conventional PMRs with pressure-driven membrane processes.

\subsection{Effect of feed temperature on photodegradation efficiency and permeate flux}

Fig. 4 compares the photodegradation efficiencies of RB5 at different feed temperatures. The results indicate that in the temperature range of $55-70{ }^{\circ} \mathrm{C}$ under microwave irradiation, the removal efficiency of RB5 for all runs reached $100 \%$ within 300 min. In addition, the photodegradation efficiency first increased with an increasing temperature below $65^{\circ} \mathrm{C}$, and then decreased as the feed temperature was further raised to $70^{\circ} \mathrm{C}$. This was attributed to the properties of MEDLs whose emission spectrum changes substantially with the feed temperature. The UV light of $254 \mathrm{~nm}$ dominates at a temperature below $65^{\circ} \mathrm{C}$; while at a temperature above $70^{\circ} \mathrm{C}$, the MEDLs will emit less UV light and even turn off [26]. In the present work, occasional lamp fails were also observed at $70^{\circ} \mathrm{C}$, which decreased the photodegradation efficiency.

The feed temperature also influenced notably the VMD process. Table 1 shows the effect of feed temperature on the pure water flux (PWF) with conventional thermostatic bath or microwave irradiation heating and the SPMDR flux in the presence of $2.0 \mathrm{~g} / \mathrm{L} \mathrm{TiO}_{2}$. The results indicate that a higher flux was observed with microwave heating or in the SPMDR than with conventional heating. It is seen that the VMD mass transfer was enhanced by microwave irradiation. Microwave irradiation led to a local temperature increase, which compensated for the temperature decrease caused by evaporation and temperature polarization. This is an obvious advantage of the developed SPMDR.

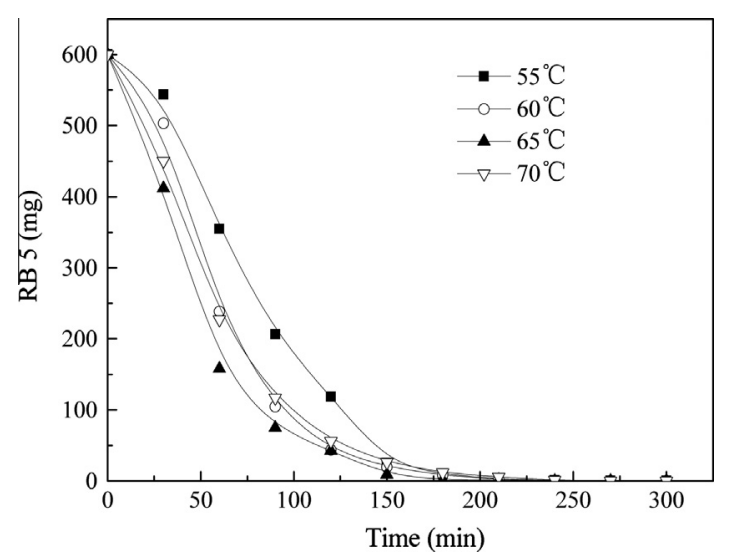

Fig. 4. Change in the RB5 amount in the feed during the photodegradation process at different feed temperatures $\left(C_{\mathrm{o}, \mathrm{RB} 5}=400 \mathrm{mg} / \mathrm{L}, \quad \mathrm{TiO}_{2}\right.$ dose $=2.0 \mathrm{~g} / \mathrm{L}, P_{\mathrm{vac}}=$ $-75 \mathrm{kPa})$. 
Table 1

Comparison of permeate fluxes under different conditions.

\begin{tabular}{lllll}
\hline Flux $\left(\mathrm{L} / \mathrm{m}^{2} \mathrm{~h}\right)$ & \multicolumn{4}{l}{ Feed temperature $\left({ }^{\circ} \mathrm{C}\right)$} \\
\cline { 2 - 5 } & 55 & 60 & 65 & 70 \\
\hline PWF (conventional heating) & 0.85 & 1.88 & 3.62 & 5.43 \\
PWF (microwave heating) & 1.52 & 2.84 & 4.64 & 6.25 \\
SPMDR $\left(\mathrm{TiO}_{2}\right.$ dose $\left.=2 \mathrm{~g} / \mathrm{L}\right)$ & 1.32 & 2.46 & 4.14 & 5.72 \\
\hline
\end{tabular}

\subsection{Decolorization and mineralization of RB5}

Fig. 5 shows the change of the solution absorption spectrum during the photodegradation process. The absorption peaks of RB5 appearing at 230, 310 and $600 \mathrm{~nm}$ could be attributed to the benzene ring, naphthalene ring and azo bond, respectively. The absorption peak at $600 \mathrm{~nm}$ (denoting the azo bond) disappeared completely after $180 \mathrm{~min}$, demonstrating an effective decolorization efficiency of the SPMDR.

The decolorization of the RB5 solution was mainly associated with the cleavage of the azo bonds. The subsequent photodegradation would break down the benzene and naphthalene rings and lead to the formation of low molecular-weight aliphatic acids, which could be further mineralized to $\mathrm{H}_{2} \mathrm{O}, \mathrm{CO}_{2}$ and inorganic anions [16].

The amounts of TOC, aliphatic acids and inorganic ions in the feed were determined at various reaction times, as shown in Fig. 6. The TOC removal showed three phases: (1) in the initial 30 min, a relatively rapid TOC removal (12\%) was observed probably because RB5 was adsorbed onto $\mathrm{TiO}_{2}$ particles besides its photodegradation; (2) in the time period of $30-180 \mathrm{~min}$, the TOC removal slowed down (only with a $10 \%$ increase), which arose from the continuous formation of aliphatic acids; and (3) in the final time period (180-300 min), the TOC was removed more quickly due to the mineralization of the aliphatic acids and a high TOC removal efficiency $(80.1 \%)$ was observed at $300 \mathrm{~min}$. The amounts of formic, acetic and maleic acids reached maximum at 210-240 min, and then decreased to $7.2,8.6$ and $21.1 \mathrm{mg}$ at $300 \mathrm{~min}$, respectively.

Fig. 7 shows the generation of inorganic ions $\left(\mathrm{SO}_{4}^{2-}, \mathrm{NH}_{4}^{+}\right.$and $\mathrm{NO}_{3}^{-}$) in the feed during the RB5 photodegradation process. The amount of $\mathrm{SO}_{4}^{2-}$ slightly increased to $8.2 \mathrm{mg}$ in the initial $150 \mathrm{~min}$, and then increased sharply to $102 \mathrm{mg}$ at $300 \mathrm{~min}$. Although much less $\mathrm{NH}_{4}^{+}$and $\mathrm{NO}_{3}^{-}$ions were formed than $\mathrm{SO}_{4}^{2-}$, their amounts in the feed exhibited a similar increasing trend. The amount of $\mathrm{NH}_{4}^{+}$was approximately three times that of $\mathrm{NO}_{3}^{-}$, indicating that the oxidation of $\mathrm{NH}_{4}^{+}$to $\mathrm{NO}_{3}^{-}$was a slow process.

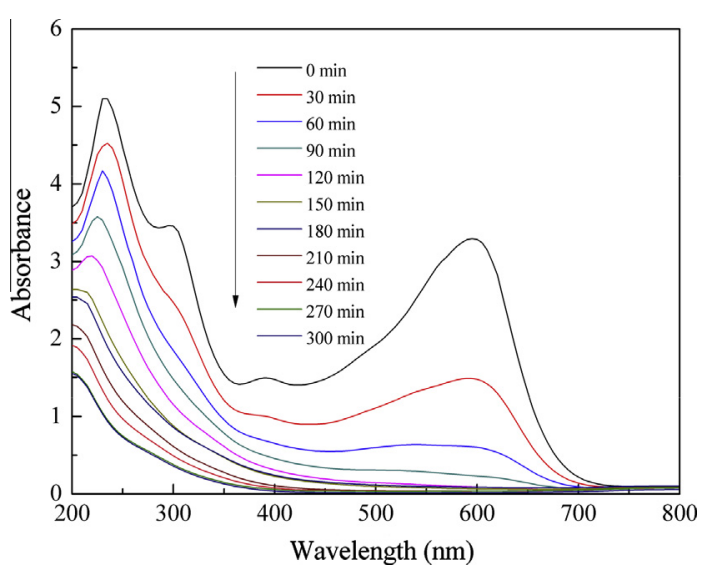

Fig. 5. Change of the solution absorption spectrum during the photodegradation process $\left(\boldsymbol{C}_{\mathbf{o}, \mathrm{RB} 5}=400 \mathrm{mg} / \mathrm{L}, \mathrm{TiO}_{2}\right.$ dose $\left.=2.0 \mathrm{~g} / \mathrm{L}, T=65^{\circ} \mathrm{C}, P_{\text {vac }}=-75 \mathrm{kPa}\right)$.

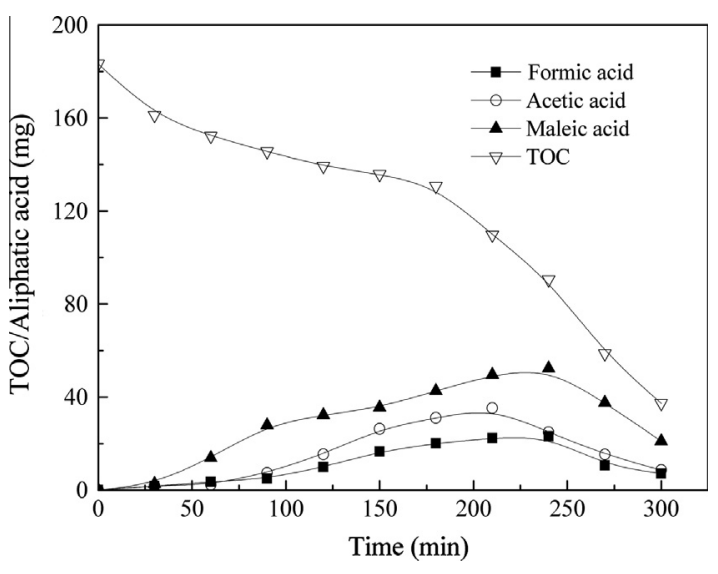

Fig. 6. Change in the amounts of TOC and aliphatic acids in the feed during the photodegradation process $\left(\boldsymbol{C}_{\mathbf{o}, \mathrm{RB} 5}=400 \mathrm{mg} / \mathrm{L}, \mathrm{TiO}_{2}\right.$ dose $=2.0 \mathrm{~g} / \mathrm{L}, T=65^{\circ} \mathrm{C}, P_{\mathrm{vac}}=$ $-75 \mathrm{kPa}$ ).

In addition, the high feed temperature $\left(65^{\circ} \mathrm{C}\right)$ would reduce the water solubility of oxygen gas, thus retarding the oxidation of $\mathrm{NH}_{4}^{+}$to $\mathrm{NO}_{3}^{-}$[16].

The initial dye concentrations were usually not higher than $100 \mathrm{mg} / \mathrm{L}$ in the conventional PMRs using UV lamps as the light source [12-17]. In comparison, the developed SPMDR could achieve an effective color and TOC removal at an initial RB5 concentration as high as $400 \mathrm{mg} / \mathrm{L}$. This may be attributed to two reasons: (1) more hydroxyl radicals $(. \mathrm{OH})$ could be generated in the SPMDR by photocatalysis assisted with microwave irradiation [27]; and (2) the partially immersed MEDLs could shorten the optical path and transfer more light energy into the solution [1].

\subsection{Permeate quality analysis}

The permeate quality of the SPMDR was analyzed, including the concentrations of $\mathrm{RB} 5$ and inorganic ions (i.e., $\mathrm{SO}_{4}^{2-}, \mathrm{NO}_{3}^{-}$and $\mathrm{NH}_{4}^{+}$), turbidity, $\mathrm{pH}$, conductivity, and the amounts of TOC and aliphatic acids. The results indicate that neither RB5 nor the target inorganic ions were detected in the permeate. The permeate turbidity was kept in a low range of $0.10-0.18 \mathrm{NTU}$, similar to that of tap water (i.e., $0.15 \mathrm{NTU}$ ). The hydrophobic PP membrane was only permeable to volatile chemicals, so the RB5 dye, $\mathrm{TiO}_{2}$ and inorganic ions were completely retained in the feed side as expected. However, in the PMRs utilizing pressure-driven membranes, complete rejection of non-volatile chemicals could not be achieved, even utilizing NF $[9,10]$.

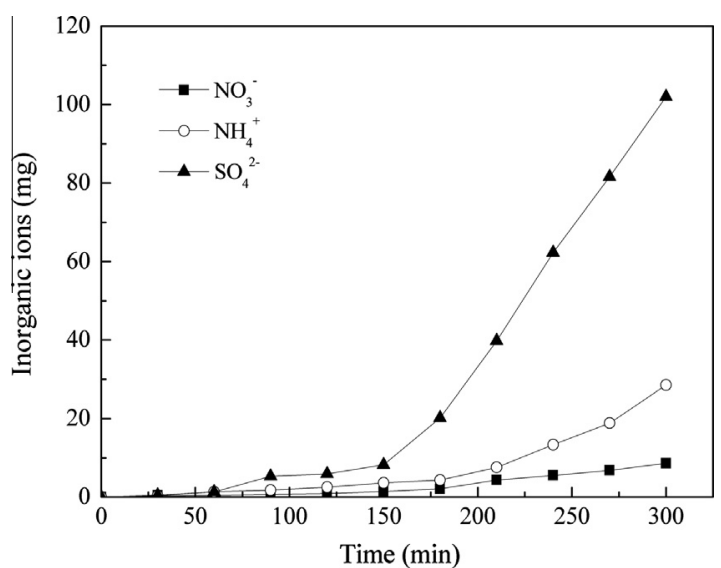

Fig. 7. Change in the amounts of inorganic ions in the feed during the photodegradation process $\left(\boldsymbol{C}_{\mathbf{o}, \mathrm{RB} 5}=400 \mathrm{mg} / \mathrm{L}, \mathrm{TiO}_{2}\right.$ dose $\left.=2.0 \mathrm{~g} / \mathrm{L}, T=65^{\circ} \mathrm{C}, P_{\mathrm{vac}}=-75 \mathrm{kPa}\right)$. 
The variations of permeate conductivity and $\mathrm{pH}$ as a function of time are shown in Fig. 8. The permeate conductivity increased from 4.2 to $28.7 \mu \mathrm{S} / \mathrm{cm}$, while the permeate $\mathrm{pH}$ decreased from 6.5 to 4.2 during the entire photodegradation process. This result implies that some organic acids could penetrate the PP membrane to reach the permeate side. As confirmed in Fig. 9, formic and acetic acids were detected in the permeate, which made a main contribution to the TOC. Maleic acid was not detected in the permeate because of its low volatility. The amount of acetic acid was always higher than that of formic acid, which is in correspondence with their concentrations in the feed (Fig. 6). The amounts of formic and acetic acids and TOC kept increasing till a maximum was reached at 201-240 min and started to decrease thereafter, which agreed well with their variations in the feed (Fig. 6). After 300 min of photodegradation, the amounts of formic and acetic acids and TOC in the permeate were determined to be $0.08,0.25$ and $0.52 \mathrm{mg}$ (or 1.83 , 5.29 and $10.6 \mathrm{mg} / \mathrm{L}$ ), respectively. Additionally, the $\mathrm{CO}_{2}$ generated from organic mineralization in the feed may also transfer to the permeate side and change the permeate $\mathrm{pH}$ and conductivity.

Although a complete rejection of organic compounds was not achieved in the SPMDR, the permeate had only a low TOC concentration Therefore, the SPMDR could produce a higher quality permeate than the PMRs utilizing pressure-driven membranes.

\subsection{Membrane fouling}

In the previous experiments examining the effect of $\mathrm{TiO}_{2}$ dose (0.5-6.0 g/L) on RB5 removal and permeate flux, each experiment was conducted for $300 \mathrm{~min}(5 \mathrm{~h})$ by using the same membrane module. Therefore, the membrane module had been working for $25 \mathrm{~h}$. The SEM images of a fresh PP membrane, the fouled membrane after $25 \mathrm{~h}$ reaction, and the rinsed membrane after $30 \mathrm{~min}$ washing with distilled water are compared in Fig. 10. During the photodegradation process, membrane samples at different reaction times $(5,15$ and $25 \mathrm{~h}$ ) were also collected for porosity and contact angle analysis.

As described above, the average permeate flux decreased from 4.56 to $3.74 \mathrm{~L} / \mathrm{m}^{2} \mathrm{~h}$ when the $\mathrm{TiO}_{2}$ dose increased from 0.5 to $6.0 \mathrm{~g} / \mathrm{L}$ (Fig. 3). The flux decline was attributed to a $\mathrm{TiO}_{2}$ cake layer formed on the membrane surface, as visible in Fig. 10b. This fouling layer would not only reduce the surface area available for water evaporation, but also decrease the heat transfer. After washing the fouled membrane with distilled water for $30 \mathrm{~min}$, the $\mathrm{TiO}_{2}$ cake layer was partially removed and some micropores were regenerated. The permeate flux increased notably to $4.05 \mathrm{~L} / \mathrm{m}^{2} \mathrm{~h}$ after membrane washing, although was not fully recovered.

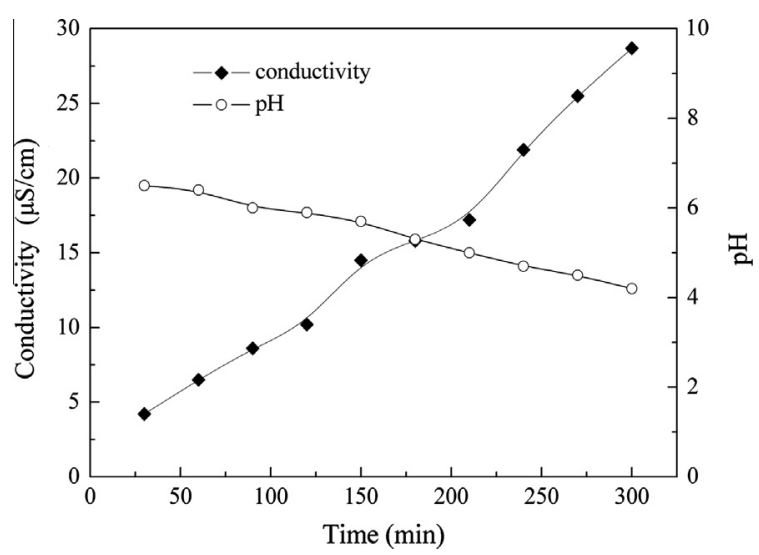

Fig. 8. Variation of the permeate conductivity and $\mathrm{pH}$ during the photodegradation process $\left(\boldsymbol{C}_{\mathbf{o}, \mathrm{RB} 5}=400 \mathrm{mg} / \mathrm{L}, \mathrm{TiO}_{2}\right.$ dose $\left.=2.0 \mathrm{~g} / \mathrm{L}, T=65^{\circ} \mathrm{C}, P_{\mathrm{vac}}=-75 \mathrm{kPa}\right)$.

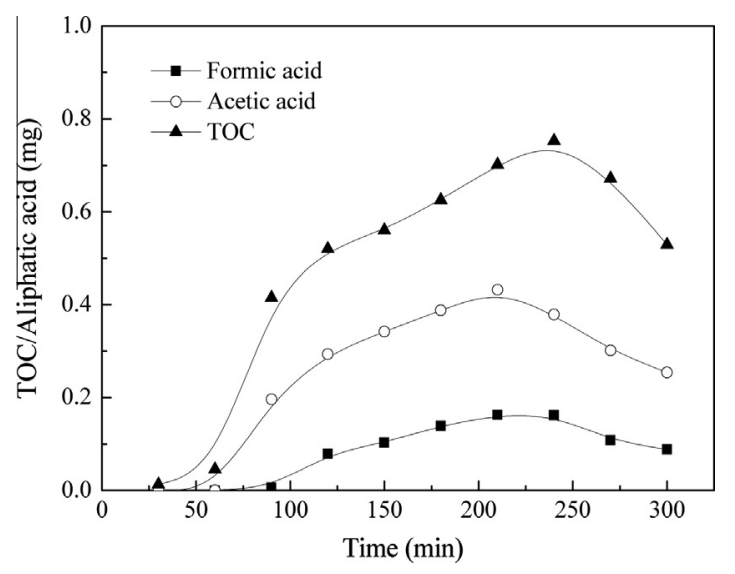

Fig. 9. Variation in the amounts of TOC and aliphatic acids in the permeate during the photodegradation process $\left(\boldsymbol{C}_{\mathbf{o}, \mathrm{RB} 5}=400 \mathrm{mg} / \mathrm{L}, \mathrm{TiO}_{2}\right.$ dose $=2.0 \mathrm{~g} / \mathrm{L}, T=65^{\circ} \mathrm{C}$, $\left.P_{\text {vac }}=-75 \mathrm{kPa}\right)$.
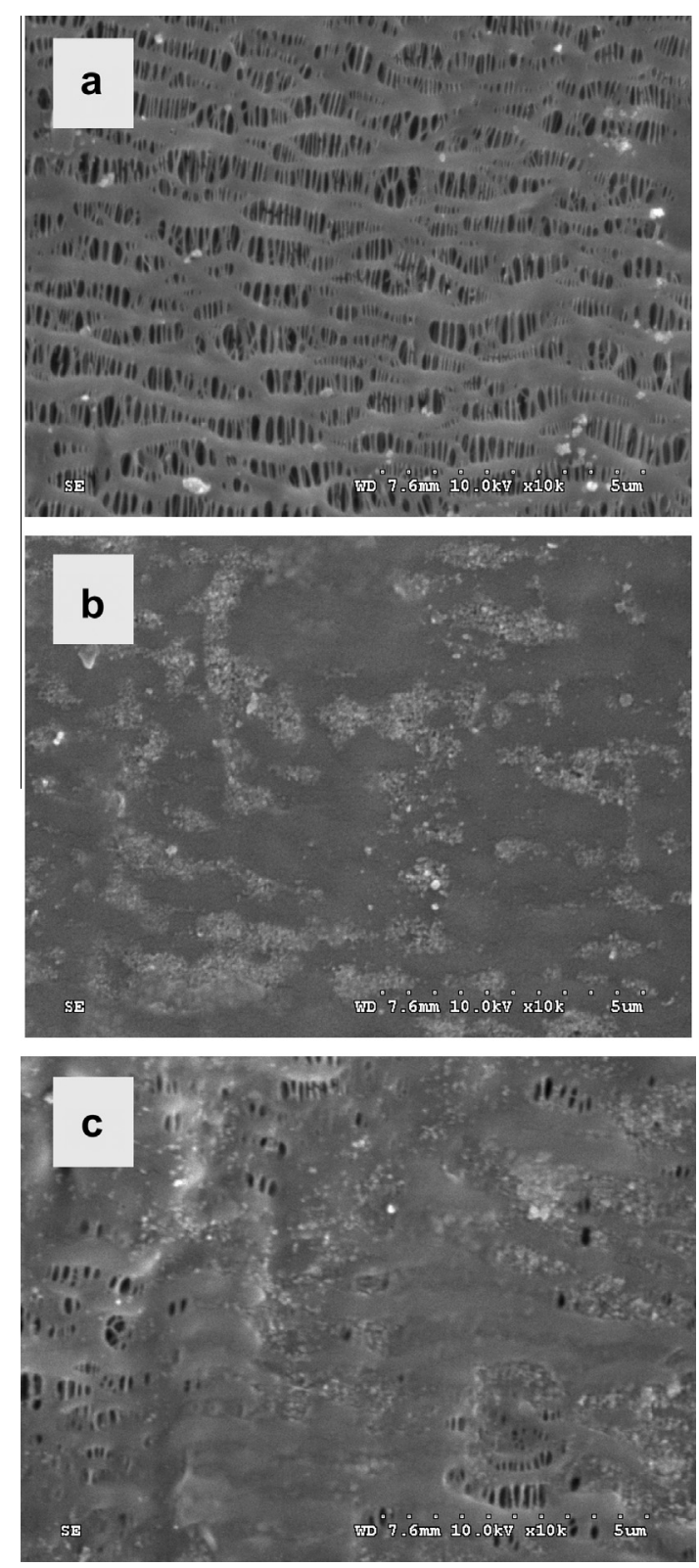

Fig. 10. SEM images of: (a) a fresh PP membrane; (b) the fouled membrane after $25 \mathrm{~h}$ reaction; and (c) the rinsed membrane (30 min washing with distilled water). 
The changes in porosity and contact angle of the fouled membrane were also examined. The porosity of the fresh PP membrane was measured to be $40.5 \%$, and it decreased slightly to $38.7 \%$, 38.5\% and $38.0 \%$ after 5,15 , and $25 \mathrm{~h}$ of reaction, respectively. After rinsing with distilled water, the membrane porosity was recovered to $40.2 \%, 39.9 \%$ and $40.0 \%$, respectively. The contact angle of the fresh PP membrane was $97.65^{\circ}$, confirming its hydrophobic nature. After reaction for 5,15 , and $25 \mathrm{~h}$, it decreased to $94.43^{\circ}, 92.24^{\circ}$ and $89.87^{\circ}$, respectively. The contact angle was recovered to $97.15^{\circ}$, $95.69^{\circ}$ and $95.08^{\circ}$ after membrane washing.

The above results show that a $\mathrm{TiO}_{2}$ layer was formed at high $\mathrm{TiO}_{2}$ doses, which decreased the membrane porosity and contact angle to some extent. However, simple membrane washing with distilled water could recover most of the permeate flux and the membrane porosity and contact angle as well. This denotes indirectly that the formed $\mathrm{TiO}_{2}$ cake layer was quite loose because of the hydrophobicity of the PP membrane used. By contrast, a compact $\mathrm{TiO}_{2}$ cake layer was usually formed on the surface of a pressure-driven membrane even at a low $\mathrm{TiO}_{2}$ dose.

\section{Conclusions}

In this study, a SPMDR with MEDLs as light source was developed and applied to degrade a synthetic dye wastewater containing $400 \mathrm{mg} / \mathrm{L}$ RB5. The results show the SPMDR was more resistant to membrane fouling than the conventional PMRs with a pressure-driven membrane process, especially in the case of a high $\mathrm{TiO}_{2}$ dose. In addition, the enhancement of microwave irradiation to the VMD mass transfer was confirmed. The SPMDR flux in the presence of $2.0 \mathrm{~g} / \mathrm{L} \mathrm{TiO}_{2}$ was higher than the PWF with conventional heating, which exemplifies an obvious advantage of the SPMDR.

A high color (100\%) and TOC (80.1\%) removal efficiency was achieved after $300 \mathrm{~min}$ photodegradation of $400 \mathrm{mg} / \mathrm{L}$ RB5 synthetic wastewater by the SPMDR. Indentified byproducts included aliphatic acids (formic, acetic and maleic acid) and inorganic ions $\left(\mathrm{SO}_{4}^{2-}, \mathrm{NH}_{4}^{+}\right.$and $\left.\mathrm{NO}_{3}^{-}\right)$. The permeate was high quality water, containing only a low TOC concentration $(10.6 \mathrm{mg} / \mathrm{L})$ and a low turbidity $(\leqslant 0.18 \mathrm{NTU})$. $\mathrm{RB} 5, \mathrm{TiO}_{2}$ and inorganic ions were completely retained in the feed side. A loose $\mathrm{TiO}_{2}$ cake layer formed on the membrane outer surface decreased module efficiency, membrane porosity and contact angle to some extent. However, they could be largely recovered after $30 \mathrm{~min}$ of washing with distilled water.

\section{Acknowledgements}

This work was sponsored by the Fundamental Research Funds for the Central Universities (TD-JC-2013-3), National Natural Science Foundation of China (Grant Nos. 51008024, 21107103) and National Undergraduate Scientific and Technological Innovation Project (Grant No. 201210022079).

\section{References}

[1] X. Zhang, G. Li, Y. Wang, Microwave assisted photocatalytic degradation of high concentration azo dye Reactive Brilliant Red X-3B with microwave eletrodeless lamp as light source, Dyes Pigm. 74 (2007) 536-544.

[2] R. Molinari, L. Palmisano, E. Drioli, M. Schiavello, Studies on various reactor configurations for coupling photocatalysis and membrane processes in water purification, J. Membr. Sci. 206 (2002) 399-415.
[3] S.S. Chin, T.M. Lim, K. Chiang, A.G. Fane, Factors affecting the performance of a low-pressure submerged membrane photocatalytic reactor, Chem. Eng. J. 130 (2007) 53-63.

[4] H.K. Shon, S. Phuntsho, S. Vigneswaran, Effect of photocatalysis on the membrane hybrid system for wastewater treatment, Desalination 225 (2008) $235-248$

[5] M.J. Rivero, S.A. Parsons, P. Jeffrey, M. Pidou, B. Jefferson, Membrane chemical reactor $(\mathrm{MCR})$ combining photocatalysis and microfiltration for grey water treatment, Water Sci. Technol. 53 (2006) 173-180.

[6] K. Sopajaree, S.A. Qasim, S. Basak, K. Rajeshwar, An integrated flow reactormembrane filtration system for heterogeneous photocatalysis. Part I. Experiments and modelling of a batch-recirculated photoreactor, J. Appl. Electrochem. 29 (1999) 533-539.

[7] K. Sopajaree, S.A. Qasim, S. Basak, K. Rajeshwar, An integrated flow reactormembrane filtration system for heterogeneous photocatalysis. Part II: Experiments on the ultrafiltration unit and combined operation, J. Appl. Electrochem. 29 (1999) 1111-1118.

[8] S. Mozia, M. Tomaszewska, A.W. Morawski, Removal of azo-dye Acid Red 18 in two hybrid membrane systems employing a photodegradation process, Desalination 198 (2006) 183-190.

[9] R. Molinari, F. Pirillo, V. Loddo, L. Palmisano, Heterogeneous photocatalytic degradation of pharmaceuticals in water by using polycrystalline $\mathrm{TiO}_{2}$ and a nanofiltration membrane reactor, Catal. Today 118 (2006) 205-213.

[10] R. Molinari, A. Caruso, P. Argurio, T. Poerio, Degradation of the drugs Gemfibrozil and Tamoxifen in pressurized and de-pressurized membrane photoreactors using suspended polycrystalline $\mathrm{TiO}_{2}$ as catalyst, J. Membr. Sci. 319 (2008) 54-63.

[11] V. Augugliaro, E. Garcia-Lopez, V. Loddo, S. Malato-Rodriguez, I. Maldonado, G. Marci, R. Molinari, L. Palmisano, Degradation of linomycin in aqueous medium: coupling of solar photocatalysis and membrane separation, Sol. Energy 79 (2005) 402-408.

[12] S. Mozia, M. Tomaszewska, A.W. Morawski, A new photocatalytic membrane reactor (PMR) for removal of azo-dye Acid Red 18 from water, Appl. Catal. B: Environ. 59 (2005) 133-139.

[13] S. Mozia, A.W. Morawski, Hybridization of photocatalysis and membrane distillation for purification of wastewater, Catal. Today 118 (2006) 181-188.

[14] S. Mozia, M. Toyoda, M. Inagaki, B. Tryba, A.W. Morawski, Application of carbon-coated $\mathrm{TiO}_{2}$ for decomposition of methylene blue in a photocatalytic membrane reactor, J. Hazard. Mater. 140 (2007) 369-375.

[15] S. Mozia, M. Tomaszewska, A.W. Morawski, Photocatalytic membrane reactor (PMR) coupling photocatalysis and membrane distillation - effectiveness of removal of three azo dyes from water, Catal. Today 129 (2007) 38.

[16] S. Mozia, A.W. Morawski, M. Toyoda, T. Tsumura, Effect of process parameters on photodegradation of Acid Yellow 36 in a hybrid photcatalysis-membrane distillation system, Chem. Eng. J. 150 (2009) 152-159.

[17] S. Mozia, Application of temperature modified titanate nanotubes for removal of an azo dye from water in a hybrid photocatalysis-MD process, Catal. Today 156 (2010) 38.

[18] K.W. Lawson, D.R. Lloyd, Membrane distillation, J. Membr. Sci. 124 (1997) 125.

[19] J. Hong, N. Ta, S. Yang, Y. Liu, C. Sun, Microwave-assisted direct photolysis of bromophenol blue using electrodeless discharge lamps, Desalination 214 (2007) 62-69.

[20] R. Liu, H. Wang, X. Zhao, S. Xiao, J. Qu, Microwave electrodeless lamp assisted catalytic degradation of X-GRL with manganese dioxides: adsorption and manganese (IV) reductive dissolution effects, Catal. Today 139 (2008) 119124.

[21] Y. Bae, S. Jung, A study of the photocatalytic destruction of propylene using microwave discharge electrodeless lamp, J. Ind. Eng. Chem. 16 (2010) 947951.

[22] Z. Ji, J. Wang, D. Hou, Z. Yin, Z. Luan, Effect of microwave irradiation on vacuum membrane distillation, J. Membr. Sci. 429 (2013) 473-479.

[23] J. Wang, L. Wang, W.X. Ruan, C. Zhang, J.B. Ji, Rheology behavior of highdensity polyethylenene/diluent blends and fabrication of hollow-fiber membranes via thermally induced phase separation, J. App. Poly. Sci. 118 (2010) 2186-2194.

[24] S.P. Kamble, S.B. Sawant, V.G. Pangarkar, Batch and continuous photocatalytic degradation of benzenesulfonic acid using concentrated solar radiation, Ind. Eng. Chem. Res. 42 (2003) 6705-6713.

[25] S. Kaneco, M. Arifur Rahmana, T. Suzuki, H. Katsumata, K. Ohta, Optimization of solar photocatalytic degradation conditions of bisphenol A in water using titanium dioxide, J. Photochem. Photobiol. A: Chem. 163 (2004) 419-424.

[26] P. Muller, P. Klan, V. Cirkva, Electrodeless discharge lamp: a prospective tool for photochemistry. Part 4. Temperature and envelope material dependent emission characteristics, J. Photochem. Photobio. A: Chem. 158 (2003) 15.

[27] S. Horikoshi, H. Hidaka, N. Serpone, Environmental remediation by an integrated microwave/UV-illumination method. 1. Microwave-assisted degradation of rhodamine-B dye in aqueous $\mathrm{TiO}_{2}$ dispersions, Environ. Sci. Technol. 36 (2002) 1357-1366. 